\title{
Astronomy in the society and culture of Estonia
}

\author{
Laurits Leedjärv \\ Tartu Observatory, 61602 Tõravere, \\ Tartumaa, Estonia \\ email: leed@aai.ee
}

\begin{abstract}
History and present state of astronomy in a small North-Eastern European country are considered. There is a rather big number (about 35) of professional astronomers in Estonia, including 21 IAU members. Through some outstanding persons, astronomy in Estonia has significant relations with the society. The same can be said about the culture. Well-developed astronomy has contributed into the cooperation of Estonia with the European Space Agency, and thus, has an indirect effect to the country's economy.
\end{abstract}

Keywords. astronomical folklore, history of astronomy, relations to the society, astronomy and culture, astronomy and economy

\section{Introduction}

Estonia is a small country in the North-Eastern Europe, on the coast of the Baltic Sea. Having been governed by Germany, Denmark, Sweden, Russia etc., Estonia became independent in 1918. In 1940, Soviet Union occupied Estonia as well as Latvia and Lithuania - the other small Baltic states. The independence of Estonia was restored only in 1991, 20 August, following which the whole Soviet Union soon disrupted. In 2004, Estonia became a member of the European Union and NATO, being thus fully integrated into Europe.

Estonia has an area of about $45000 \mathrm{~km}^{2}$ and a population of about 1.4 million. Could such a small country have significant astronomical activity? Indeed, it can. In what follows, I will try to show that the rôle of astronomy in the society and culture of a small country could be even more important than in some big states. I shall briefly review Estonian astronomical folklore, history and present state of the professional astronomy. Thereafter, some examples on the connection of astronomy with the society and with the culture will be given. Finally, some conclusions will be drawn.

\section{Astronomy in Estonia: from myths to modern telescopes}

Most likely, every nation on the Earth has its own myths and believings about the sky. There are uncountable ways, how stars are combined into constellations. Estonian folklore also has a rich astronomical heritage, including popular names for more than 20 constellations, specific name for the Milky Way etc. While, for example, Greek heavenly mythology is very poetic and complicated, Estonian names of constellations and relevant myths are rather simple, connected to everyday rural life. Let some examples here be The Big Waggon for Ursa Major, the Small Waggon for Ursa Minor, the Bowl for Bootes, the Heavenly Cross for Cygnus, the Flail and the Rake for Orion, the Base of the Haystack for Corona Borealis. The brightest star of the Northern sky Sirius has been called Orjatäht in Estonian, which means the Slave's Star. The story tells that the poor slaves were forced 
to work until the rise of the Slave's Star during the threshing in Autumn. At the latitude of Estonia (58-59 degrees North), Sirius arises well after midnight in September. So, the working day of the slaves was very long, and finally the star showed mercy to them.

In Estonian language and other relative languages from the Finno-Ugric group of languages, there is a specific name for what is called a Milky Way in most of the European languages - Linnutee which means a Birds' Way. As at some time in Autumn nights the Milky Way is seen almost directing from north to south, just above the heads, in the Nordic countries, there seemed to be a common thinking that migrating birds are flying to south along the Birds' Way.

The University of Tartu was established in 1632 by the Swedish king Gustav II Adolf under the name of Academia Gustaviana. It is known that some elements of astronomy were taught in this university, however, there was no real astronomical research. Professional astronomy started in the beginning of 19th century, when Estonia belonged to the Russian Tsarist Empire, and the University of Tartu was re-opened in 1802 as a Germanlanguage university (Zhelnin 1969) In the same year, the first astronomer-observer was employed by the University. Construction works of the observatory started in 1808 and were finished by the end of 1810. Regular astronomical observations, however, were not started before 1814. By this time, Professor Friedrich Georg Wilhelm Struve (1793-1864) had purchased necessary minimum equipment for the university observatory. In 1824 , Struve succeeded to obtain the 9-inch refractor from Joseph von Fraunhofer workshop in Munich. This telescope occured to be one of the best refractors in the world. Among other tasks, Struve used this telescope for first in the world measurements of stellar parallax (Vega) and for compiling the catalogue of visual double stars. Struve was also a geodesist who arranged measurements of the length of the meridian arc stretching from Hammerfest, Norway to the Black Sea (now Ukraine). In 2005, Struve Geodetic Arc was included into the UNESCO World Heritage list.

In 1839, Struve left from Tartu to Pulkovo (near Sankt Petersburg, Russia) to establish a new observatory there. Observatory in Tartu continued to work successfully throughout 19th century, under the leadership of several more or less outstanding astronomers (Mädler, Clausen, Pokrowski, Levitski et al.). In the first half of 20th century, the most distinguished Estonian astronomer Ernst Julius Öpik (1893-1985) gained fame to Tartu Observatory. Öpik was an universal astronomer, contributing to many fields of the 20th century astronomy (including, e.g. theory of stellar evolution and hazardous asteroids). One of the most famous of his works is the determination of the distance to the Andromeda nebula in 1922 (Öpik 1922). In 1944, Öpik emigrated from Estonia, escaping from the upcoming Soviet occupation. He spent most of the remaining life in Armagh Observatory, Northern Ireland, with frequent trips to Maryland, USA. Besides being a well-known astronomer, Öpik was also a composer and a talented piano player.

From the time after the World War II, one should mention Professor Grigori Kusmin (1917-1988), a prominent specialist in stellar dynamics. He derived the expression for the third integral of motion (1953) which is widely used in stellar dynamics, as well as the concept of "Kusmin disk" in galaxies (1956) (see e.g. Kusmin 1964). Student of Grigori Kusmin, Jaan Einasto (b. 1929) has become the most well-known present-day astronomer in Estonia. He was one of the discoverers of dark matter in 1974 (Einasto et al. 1974), and made first claims on the regular cell-like structure of the Universe in 1977, followed by further observational confirmations in 1997 and later (Einasto et al. 1997). In spite of his age, Professor Jaan Einasto is still actively working in astronomy. In February 2009, a minor planet 11577 was named Einasto on the occasion of his 80th birthday.

One more name should be mentioned in relation to the development of astronomical technology - Bernhard Voldemar Schmidt (1879-1935), inventor of the novel coma-free 
optical system for the wide-field telescopes was born on the small Nargen island (Naissaar) close to Tallinn, the capital of Estonia.

\section{Astronomy in Estonia at present}

A new observatory was designed and built about 20 kilometers out of Tartu, in the Tõravere village, starting from 1958. Official opening took place in 1964. The first telescopes were the $70 \mathrm{~cm}$ reflector, two $50 \mathrm{~cm}$ reflectors, and several smaller ones. In 1976, the 1.5 meter reflector AZT-12 was inaugurated. It has since been the biggest telescope in Estonia, and actually in the whole Northern Europe. The $60 \mathrm{~cm}$ Zeiss reflector was inaugurated in 1998. At present, only these two telescopes are in active use, the 1.5 meter one for stellar spectroscopy, and the $60 \mathrm{~cm}$ for photometric observations.

The staff of the Tartu Observatory includes altogether about 75 people in recent years. This number includes both part-time workers (e.g. Ph.D. students often work on parttime basis) and technical personnel. The number of researchers and engineers extends to about 55 . Of them, about 35 are active in astronomy, and about 20 in atmospheric physics. During the last about 60 years, Tartu Observatory has always involved a significant research in atmospheric physics, meterorology, remote sensing, and other Earth and space related disciplines.

Astronomical research can be divided into two more or less equal parts: cosmology and stellar physics, the former including also physics of galaxies. As the climate in Estonia is not very favourable for astronomical observations, much attention is turned to theoretical modelling and to usage of observational data available from other observatories and public databases (see http://www.aai.ee for further information).

Tartu Observatory is practically the only professional observatory in Estonia. There is a small observatory belonging to the Tallinn University of Technology; people who are working there are rather active in teaching and popularization of science, but their research work is related to Tartu Observatory. Amateur astronomers, on the other hand, are becoming more active and better organized in recent years. Many amateur telescopes are available, annual summer camps are held etc.

As of January 2009, there were 21 IAU members in Estonia. Divided over the population of about 1.4 million, this yields 15 IAU members per one million inhabitant - the largest number in the world after Vatican! On the XXVIIth General Assembly of IAU in Rio de Janeiro, three more new members from Estonia were adopted.

\section{Astronomers in the Estonian society}

One can define at least three significant rôles of astronomers which are more or less relevant in every country:

- world-class fundamental research;

- teaching in the universities;

- popularization and dissemination of knowledge.

Estonian astronomers are active in all those fields. Their mission in general would be arising awareness of the rôle of science in the society. Sometimes, especially when there are remarkable fluctuations and cataclysms in the society, astronomers could be more deviated from their everyday work. This happened in Estonia in late 1980s - early 1990s, during the so called Singing Revolution which eventually led to the restoration of the independence. Many astronomers were active in people movements and politics in this time, but most of them returned to research when the society calmed down. Due to difficult economic conditions, the newly-born Estonia was not able to offer job to all the 
astronomers and related technical personnel employed in the Soviet time. Some active younger people left astronomy voluntarily, creating their own enterprises or finding other jobs; some other people were forced to leave.

Some astronomers, however, moved to politics and remained there. As an example, let's mention Mr. Kalle Jürgenson who started as a head of the local municipality, and was elected to the Member of the Parliament of Estonia (Riigikogu) in 1992. Mrs. Liia Hänni was the Member of the Parliament since 1990 already. She had also worked as the Minister for economic reforms in 1990s. In 2007, after retiring from active politics, she worked as an adviser to the Parliament of Kosovo. Professor Ene Ergma who used to teach at the University of Tartu moved to the politics more recently, in 2003 only. She made a very spectacular career, becoming immediately a Speaker (Chairperson) of the Parliament of Estonia, the second important person after the President according to the Constitution of Estonia. She continues on the same post after the elections in 2007. At the same time, she is the only woman member of the Academy of Sciences of Estonia.

\section{Astronomy and culture}

Culture in its broadest sense always includes astronomy (at least, in my personal view). In everyday life, however, science and culture are often considered as separate phenomena. In Estonia, there is at least one example which bridges these two fields - a composer Urmas Sisask (b. 1960). He is a very advanced amateur astronomer, and at the same time, very talented composer who has got inspiration for many of his masterpieces directly from the starry sky (cycles of piano pieces "Northern Sky" and "Southern Sky", Perseids, RX Cassiopeiae, Symbiotic Symphony etc.). In his earlier creative period, he used to convert many kinds of astronomical frequencies, derived from the orbital periods of binary stars, planets etc. to acoustical frequencies. He has established the first and only musical observatory in Estonia where he often organizes concerts and demonstrates his "Keyboard of the Universe".

Urmas Sisask has expressed his musical Credo as follows: "Our 14 billion years old Universe is a huge organ invented by Jehova. Due to the force of gravity galaxies, stars, planets, comets and other constellations form gigantic organ pipes. That is the Credo of my life and work. To learn the harmony of the musical instrument of the Universe and to make it heard to the people is my mission. Thus, I do not consider myself a composer but a recorder of music."

Bernhard Schmidt, a talented inventor, but somewhat lonely person of complicated character, has also been reflected in the Estonian culture. Jaan Kross (1920-2007), the most famous 20th century Estonian novelist, has written the novel "Vastutuulelaev" (Ship against the wind) about him. Interestingly, the world-famous Estonian conductor Tõnu Kaljuste (b. 1953) has acquired the birthplace of Bernhard Schmidt on the Nargen island near Tallinn. He is very much interested in the Schmidt's legacy. He has also arranged erecting a concert and theatre hall on that small island where many cultural performances are held in summer time. In 2006, a piece about Bernhard Schmidt, based on the Jaan Kross' novel was played there.

In 2004, the 125th birth anniversary of Bernhard Schmidt was among other activities celebrated by issuing a stamp and a postcard. At the risk of omitting several other relations of astronomy and culture, let's mention by the end of this Section that the lecture hall of the Tartu Observatory is sometimes used for cultural performances as well - concerts, theatre, public lectures etc. As one fo the most recent examples, a chamber symphony orchestra played the music by Urmas Sisask. In 2007, a student's performance, 
including popular-scientific lectures, music, light show, poetry etc. took place in the premises of the Tartu Observatory.

\section{Conclusions}

There is a relatively big number of professional astronomers in Estonia. In part, we can see a remnant of the Soviet system of research institutes here. At the same time, we should take advantage of this high percentage, and try to be visible in the society as much as possible. To some extent, we have been successful in this attempt. My colleague Dr. Jaan Pelt has found an interesting "correlation" that astronomy has developed well when Estonia has been included into bigger communities:

- The Russian empire in 19th century;

- Soviet Union in 1940-1991;

- European Union since 2004.

The latter still needs to be proved, but there are at least first signs: significant funds for the renovation of the research infrastructures have been retrieved from the European structural funds, and Tartu Observatory is one of the awardees, starting renovation of its main building and constructing an annex to it soon.

Estonia is developing active cooperation with the European Space Agency (ESA) now. The first cooperation agreement was signed in June 2007, and the next step, becoming an European Cooperating State is foreseen in late 2009. At least in part, one can see well-developed astronomical research as a reason why Estonia is interested in cooperation with ESA, and ESA is interested in such a small country as Estonia. In more detail:

- long historical traditions

- world-renown achievements

- relatively big number of astronomers nowadays

- experience in Soviet space research programmes

- synergy of astronomy and atmospheric physics in the Tartu Observatory

have created solid foundation to participate in the European first-rank high technology space projects.

ESA is not only a research organization, but first of all, a concentration of high technology and engineering culture. Estonian high-tech companies would benefit from the cooperation with ESA. And so, we can see here how well-developed astronomy can have at least indirect effect on the country's economy.

\section{Acknowledgements}

The author is thankful to the organizers of the IAU Symposium 260 for encouraging to make an oral report, for offering a financial support, and finally, for the patience while waiting for the manuscript of the present paper. This work and attendance of the Symposium was in part supported by the Estonian Ministry's of Education and Research target-financed project SF0060030s08.

\section{References}

Einasto, J., Kaasik, A., \& Saar, E. 1974, Nature, 250, 309

Einasto, J., Einasto, M., Gottlöber, S., Müller, V., Saar, V., Starobinsky, A. A., Tago, E., Tucker, D., Andernach, H., \& Frisch, P. 1997, Nature, 385, 139

Kusmin, G. G. 1964, Tartu Astrofüüs. Obs. Publ., 34, 457

Öpik, E. 1922, ApJ, 55, 406

Zhelnin, G. 1969, Tartu Astrofüüs. Obs. Publ., 37, 5 